\title{
Long-term outcome of surgically treated patients with corrected transposition of the great arteries
}

\author{
Viktor Hraska, MD \\ Brian W. Duncan, MD \\ John E. Mayer, Jr, MD ${ }^{\mathrm{c}}$ \\ Michael Freed, MD ${ }^{d}$ \\ Pedro J. del Nido, MD $^{\mathrm{c}}$ \\ Richard A. Jonas, $\mathrm{MD}^{\mathrm{e}}$
}

From the Department of Pediatric Cardiac Surgery, ${ }^{\mathrm{a}}$ University Hospital HamburgEppendorf, Germany; the Department of Pediatric Cardiac Surgery, ${ }^{\text {b }}$ Children's Hospital at the Cleveland Clinic, Cleveland, Ohio; the Departments of Cardiovascular Surgery ${ }^{\mathrm{c}}$ and Cardiology, ${ }^{\mathrm{d}}$ Children's Hospital, Boston, Mass; and Children's National Medical Center, ${ }^{\text {e Washington, DC. }}$

Received for publication Dec 2, 2003; revisions received Feb 5, 2004; accepted for publication Feb 26, 2004.

Address for reprints: Richard A. Jonas, MD, Cardiac Surgery, Children's National Medical Center, 111 Michigan Ave NW, Washington, DC 20010 (E-mail: rjonas@ cnmc.org).

J Thorac Cardiovasc Surg 2005;129:182-91 $0022-5223 / \$ 30.00$

Copyright $\odot 2005$ by The American Association for Thoracic Surgery

doi:10.1016/j.jtcvs.2004.02.046
Objectives: The purpose of the study was to examine long-term outcome after traditional surgical treatment of corrected transposition of the great arteries to provide a basis for comparison with new procedures, such as the double-switch or Senning-Rastelli procedures.

Methods: Patient- and procedure-related variables in 123 patients with corrected transposition and 2 functional ventricles operated on between 1963 and 1996 were analyzed. Patients with intracardiac procedures underwent either a traditional 2-ventricle repair or a Fontan procedure.

Results: The 1-, 5-, 10-, and 15-year survivals after the operation were $84 \%, 75 \%$, $68 \%$, and $61 \%$, respectively. Patients requiring tricuspid valve replacement (27 patients $)$ at any time during follow-up had a significantly worse outcome $(P<.001$; hazard ratio, 4.4), whereas the best outcome was seen in patients undergoing the Fontan procedure (17 patients, 0 deaths). Right ventricular end-diastolic pressure of greater than $17 \mathrm{~mm} \mathrm{Hg}$ before the operation $(P<.0001)$, complete heart block after the operation $(P=.001)$, subvalvular pulmonary stenosis $(P=.013)$, Ebstein malformation of the tricuspid valve $(P=.025)$, and preoperative systemic (right) ventricular dysfunction $(P=.041)$ were identified as risk factors for death at any time by means of univariate analysis. Ebstein malformation of the tricuspid valve $(P$ $=.036$; hazard ratio, 1.5 ) was identified as a risk factor for death by multivariate analysis.

Conclusions: The long-term outcome of patients with corrected transposition after a classic surgical approach is unsatisfactory. The poorest outcome was seen in patients who required tricuspid valve replacement either at their initial operation or later during follow-up. Alternative surgical approaches, such as the double-switch, Senning-Rastelli, or Fontan procedures, are likely to have better long-term results, especially in the highest risk groups.

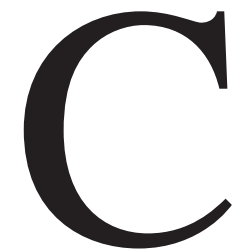
ongenitally corrected transposition of the great arteries (ccTGA) is a rare condition characterized by atrioventricular and ventriculoarterial discordance. This condition comprises less than $1 \%$ of all congenital heart defects. According to the Van Praagh nomenclature, typical segmental anatomy is $\{\mathrm{S}, \mathrm{L}, \mathrm{L}\}$ with situs solitus and \{I,D,D $\}$ with situs inversus. ${ }^{1,2}$ The clinical presentation generally depends on associated cardiac lesions, one or more of which occurred in all patients in this series. All pathophysiologic subgroups are characterized by a morphologically right ventricle functioning as the systemic ventricle, with the tricuspid valve (TV) serving as the systemic atrioventricular valve. The purpose 


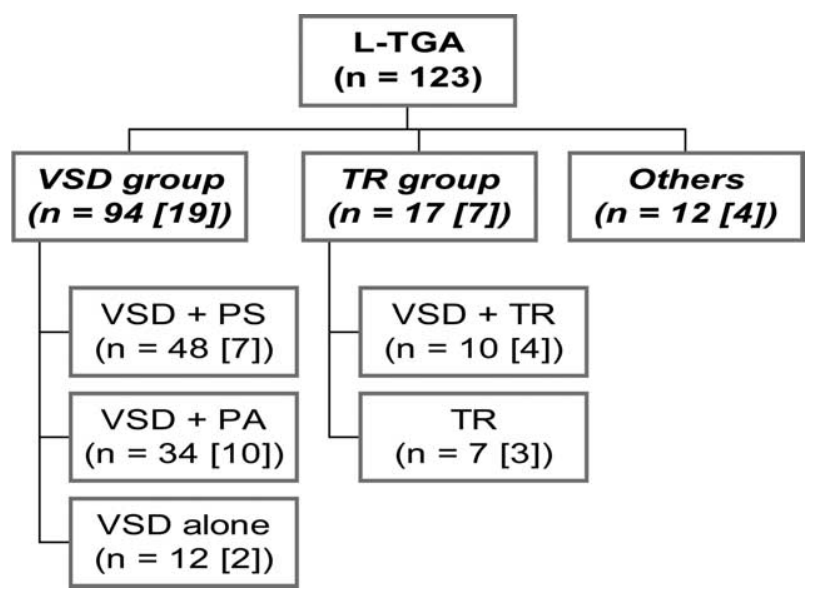

Figure 1. Block analysis by diagnostic group. Numbers of total mortality are in brackets. L-TGA, Corrected transposition of the great arteries; VSD, ventricular septal defect; $T R$, tricuspid regurgitation; $P S$, pulmonary stenosis; $P A$, pulmonary atresia.

of the study was to examine long-term outcome after traditional surgical treatment of corrected transposition of the great arteries to provide a basis for comparison with new procedures, such as the double switch or Senning-Rastelli procedures.

\section{Methods}

\section{Patient Population and Data Acquisition}

One hundred twenty-three patients with 2 functional ventricles with segmental anatomy $\{\mathrm{S}, \mathrm{L}, \mathrm{L}\}$ or $\{\mathrm{I}, \mathrm{D}, \mathrm{D}\}$ operated on at Children's Hospital, Boston, between 1963 and 1996 were identified from the database of the Departments of Cardiac Surgery and Cardiology. Medical records, preoperative and postoperative echocardiographic data, and cardiac catheterization data and operative notes were reviewed. Long-term follow-up was obtained by review of patient records and clinic notes.

\section{Patient-Related Variables}

The morphology of associated lesions was classified on the basis of preoperative cardiac catheterization and echocardiography, as well as operative findings. Atrioventricular valve regurgitation was judged as absent, trivial, mild, moderate, or severe. Right (systemic) and left (pulmonary) ventricular function were judged as normal, mildly decreased, moderately decreased, or severely decreased. The onset of complete heart block ( $\mathrm{CHB}$ ) was assumed to occur at the time it was first documented by means of electrocardiography (Appendix 1).

Patients were placed into 6 diagnostic groups according to their underlying anatomy and pathophysiology: hemodynamically significant ventricular septal defect (VSD) with pulmonary stenosis (VSD+PS); hemodynamically significant VSD with pulmonary atresia (VSD+PA); hemodynamically significant VSD alone (VSD); hemodynamically significant VSD with tricuspid regurgitation (more than mild; VSD+TR); TR alone; or other (Figure 1).

\section{Procedure-Related Variables}

On the basis of the surgical approach, patients were placed in one of 2 categories: patients who underwent only palliative procedures and patients who underwent intracardiac repair. Patients who underwent intracardiac repair had either a 2-ventricle repair or a Fontan-type operation. Patients with a 2-ventricle type of repair were further subdivided according to the type of operation into 3 groups: VSD operation, tricuspid valve replacement (TVR) or repair, or other (Appendix 2).

\section{Postoperative Outcome Variables}

TV dysfunction after the operation was defined as the need for TVR or TV function that deteriorated after the operation to moderate or severe incompetence. Right ventricular (RV) dysfunction after the operation was defined as being present when it was worse after the operation, with moderately or severely decreased function (Appendix 2).

\section{Statistical Analysis}

Data were analyzed with a statistical program (JMP Statistical Analysis, Cary, NC). The primary outcome variable was nontransplanted survival after the operation. Early failure was defined as death or heart transplantation within 30 days of the operation, and late failure was defined as death or transplantation beyond 30 days after the operation. Multiple clinical variables were analyzed for their possible effect on overall survival by using the log-rank test for categorical variables and the Cox proportional hazards model for continuous variables. For continuous variables, cutoff points were also considered. Variables that were significant at the .1 level in univariate analysis were included in a multivariate Cox proportional hazards regression model. A significance level of .05 was required for retention in the multivariate model. The Kaplan-Maier method was used to estimate probabilities of freedom from reoperation, RV failure, and TV failure. Survival probabilities and $70 \%$ confidence intervals were calculated at 5-year intervals.

Subgroups were compared with the use of the log-rank test. The effect of TVR on survival was examined by using TVR as a time-varying covariate in a Cox proportional hazards model. Patients lost to follow-up were censored in analyses of survival and other outcomes.

\section{Results}

General

Between 1963 and 1996, 123 patients (49 female and 74 male patients) with ccTGA and associated lesions potentially suitable for biventricular repair underwent a surgical procedure. Associated lesions are listed in Appendix 1. One hundred three $(84 \%)$ patients had $\{$ S,L,L $\}$ segmental anatomy, and $20(16 \%)$ patients had $\{$ I,D,D $\}$ segmental anatomy.

\section{Follow-up and Survival}

Patients were followed for a median of 5.2 years (range, 0.1-34 years). Considering both early and late events, the probability of survival from the time of the operation was $91 \%$ (70\% confidence limits, $88 \%-94 \%$ ) at 1 year, $81 \%$ 


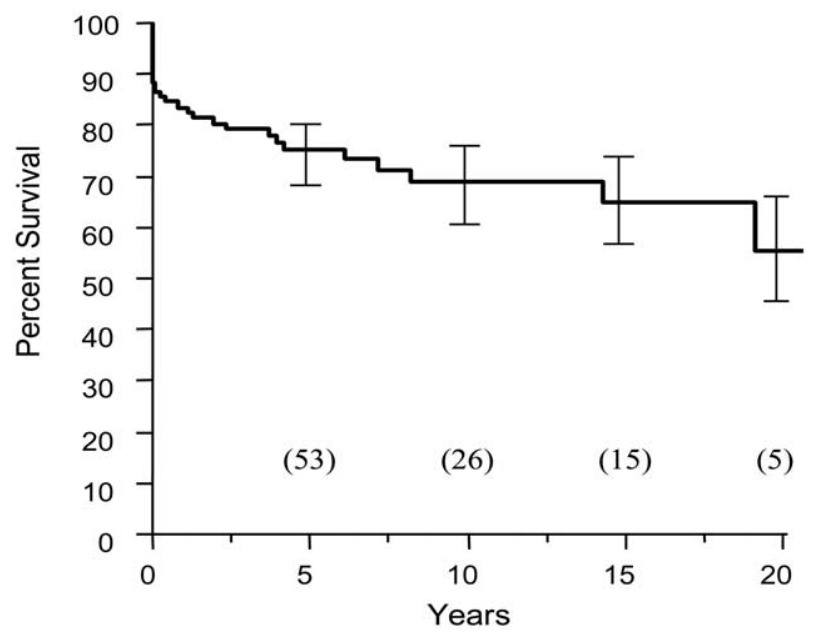

Figure 2. The probability of survival, in years, for the whole group ( $n=123$ ). Numbers of patients at risk are in parentheses. Error bars indicate $70 \%$ confidence limits.

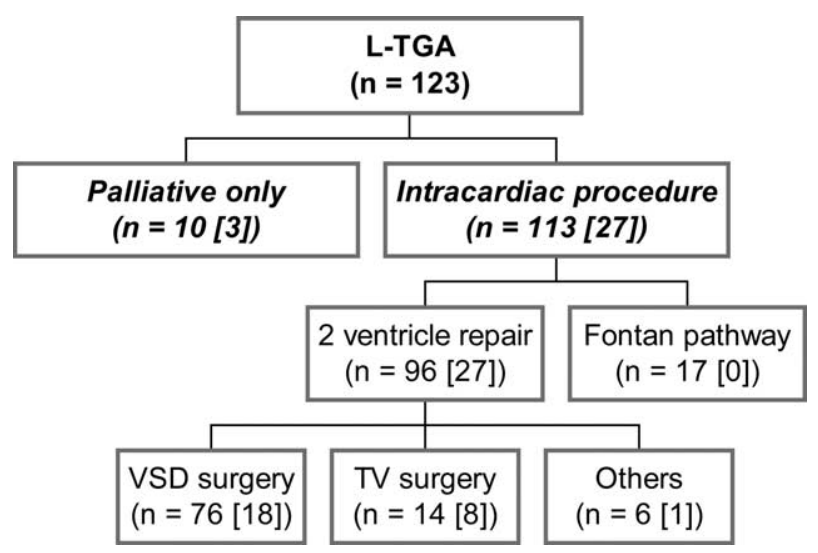

Figure 3. Block analysis by surgical approach. Numbers of total mortality are in brackets. L-TGA, Corrected transposition of the great arteries; VSD, ventricular septal defect; $T V$, tricuspid valve.

(70\% confidence limits, $77 \%-85 \%)$ at 5 years, $72 \%(70 \%$ confidence limits, 67\%-77\%) at 10 years, $67 \%(70 \%$ confidence limits, $61 \%-73 \%$ ) at 15 years, and $59 \%$ (70\% confidence limits, 52\%-66\%) at 20 years (Figure 2).

\section{Analysis by Diagnostic Groups}

The VSD+PS group exhibited the greatest survival in comparison with other diagnostic groups $(P=.046$, Figure 1$)$.

Analysis by Surgical Approach: Palliative Procedures Versus Intracardiac Repair

Mortality by surgical approach is summarized in Figure 3. Causes of early and late death are summarized in Appendix 3.

Palliative procedure only. Ten patients had palliative procedures only, with 7 (70\%) survivors. The median age at

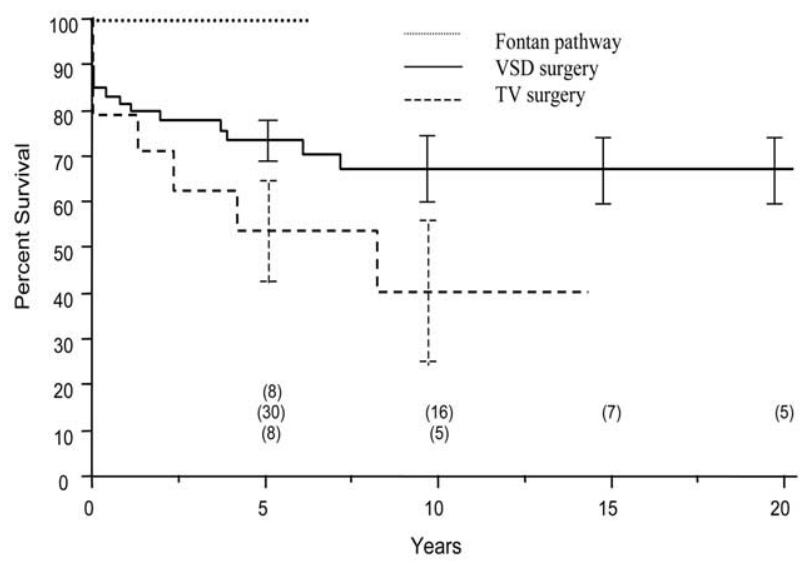

Figure 4. Survivals for the following operative groups: Fontan pathway (dotted line; $\mathbf{n}=17$ ), VSD surgery (solid line; $\mathbf{n}=76$ ), and TV surgery (dashed line; $n=14$ ). Numbers of patients at risk are in parentheses. Error bars indicate $70 \%$ confidence limits. VSD, Ventricular septal defect; $T V$, tricuspid valve.

TABLE 1. Predictors for death: intracardiac procedure $(\mathbf{n}=$ 113)

\begin{tabular}{lccc}
\hline & & \multicolumn{2}{c}{ Multivariate analysis } \\
\cline { 3 - 4 } Variable & $\begin{array}{c}\text { Univariate } \\
\boldsymbol{P} \text { value }\end{array}$ & $\begin{array}{c}\text { Hazard } \\
\text { ratio }\end{array}$ & $\boldsymbol{P}$ Value \\
\hline Subvalvular PS & .013 & & \\
Ebstein malformation of TV & .025 & 1.5 & .036 \\
RVEDp $>17 \mathrm{~mm} H g$ (before & $<.0001$ & & \\
$\quad$ the operation) & & & \\
Preoperative RV dysfunction & .041 & \\
CHB after the operation & .001 &
\end{tabular}

PS, Pulmonary stenosis; TV, tricuspid valve; RVEDp, right ventricular enddiastolic pressure; $R V$, right ventricular; $C H B$, complete heart block.

operation was 7.9 years. Patients were followed for a median of 16.6 years. Three patients were lost to follow-up. Three patients died: one early death was due to sepsis, and 2 late deaths were due to hemoptysis in combination with profound cyanosis because of inadequate pulmonary blood flow. Univariate analysis demonstrated that the longest survival after a palliative operation was associated with the VSD + PS diagnostic group $(P=.032)$.

Intracardiac procedure. An intracardiac procedure was performed in 113 patients, with 99 (88\%) early survivors. The median age at the time of the operation was 4.1 years. The patients were followed for a median of 3.9 years, with 16 patients lost to follow-up. The 1-, 5-, 10-, and 15-year survivals were $84 \%$ (70\% confidence limits, $80 \%-88 \%$ ), $75 \%$ (70\% confidence limits, 70\%-80\%), 68\% (70\% confidence limits, $62 \%-73 \%$ ), and $61 \%$ (70\% confidence limits, $53 \%-69 \%$ ), respectively. 


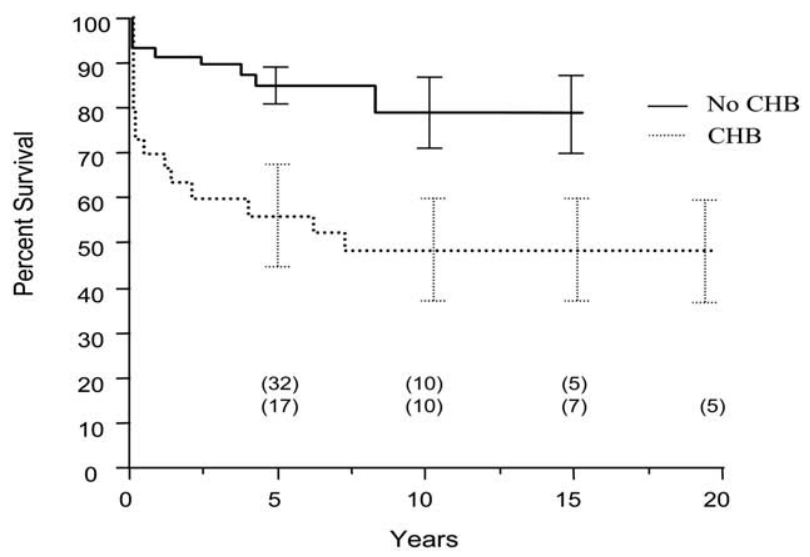

Figure 5. Survivals for patients with CHB (dotted line; $\mathbf{n}=35$ ) and without CHB (solid line; $\mathbf{n}=78$ ). Numbers of patients at risk are in parentheses. Error bars indicate $70 \%$ confidence limits. CHB, Complete heart block.

TABLE 2. Predictors for complete heart block: intracardiac procedure

\begin{tabular}{lc}
\hline Variable & Univariate $\boldsymbol{P}$ value \\
\hline Operation before 1981 & .013 \\
Nonoperative group Fontan pathway & .006 \\
\hline
\end{tabular}

Significant differences $(P=.006)$ were apparent among the surgical groups. Patients requiring TVR at their initial operation demonstrated the shortest survival (6/14 [43\%] survivors). The best outcome was seen in patients undergoing a Fontan procedure (17 patients, 0 deaths, no heart block; Figure 4).

Univariate and Multivariate Analysis of Preoperative and Immediate Postoperative Variables Affects Survival for Patients Undergoing Intracardiac Procedures

Univariate analysis demonstrated several preoperative and immediate postoperative variables associated with failure (death or transplantation) for patients undergoing an intracardiac procedure. These included morphology of the systemic (tricuspid) atrioventricular valve and preoperative systemic (right) ventricular function. Postoperative CHB was also an important risk factor leading to an adverse outcome. Ebstein malformation of the TV was identified as a risk factor for death by means of multivariate analysis (Table 1).

CHB in Patients Undergoing Intracardiac Procedures Thirty-one (28\%) of the 109 patients without CHB preoperatively had $\mathrm{CHB}$ as a postoperative complication after intracardiac repair. Atrial fibrillation and atrial flutter were

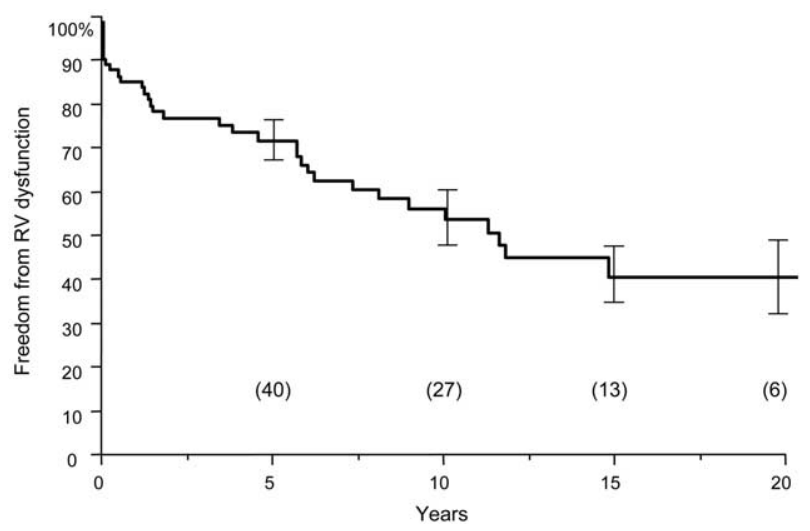

Figure 6. Freedom from right ventricular dysfunction after 2-ventricle intracardiac procedure (75 patients analyzed). Numbers of patients at risk are in parentheses. Error bars indicate $\mathbf{7 0 \%}$ confidence limits. $R V$, Right ventricular.

TABLE 3. Predictors for right ventricular dysfunction

\begin{tabular}{lccc}
\hline & Univariate & \multicolumn{2}{c}{ Multivariate analysis } \\
\cline { 3 - 4 } Variable & $\boldsymbol{P}$ value & Hazard ratio & $\boldsymbol{P}$ value \\
\hline Ebstein malformation of TV & $<.0001$ & 2.2 & $<.0001$ \\
TVR & $<.0001$ & & \\
CHB after the operation & .017 & & \\
\hline
\end{tabular}

$\overline{T V}$, Tricuspid valve; TVR, tricuspid valve replacement; $C H B$, complete heart block.

noted postoperatively in $4(4 \%)$ and $2(2 \%)$ patients, respectively. Patients without CHB had a significantly better outcome compared with patients with $\mathrm{CHB}(P=.003$, Figure 5). Univariate analysis of risk factors for $\mathrm{CHB}$ are listed in Table 2. The incidence of CHB significantly decreased after 1981 because of implementation of a new approach to VSD closure. Before 1981, 28 patients underwent intracardiac repair with 12 (43\%) cases of postoperative CHB versus 85 patients operated on after 1981 with 19 (22\%) cases of postoperative CHB.

\section{RV Dysfunction in Patients Undergoing Intracardiac}

Procedures

RV dysfunction occurred in 33 (44\%) of 75 patients for whom data were available (data were unavailable in 28 patients). The 1-, 5-, 10-, 15-, and 20-year freedom from RV dysfunction after 2-ventricle intracardiac repair was $88 \%$ (70\% confidence limits, $81 \%-89 \%$ ), $73 \%$ (70\% confidence limits, $68 \%-78 \%$ ), $57 \%$ (70\% confidence limits, 50\%-64\%), $43 \%$ (70\% confidence limits, 36\%-50\%), and 39\% (70\% confidence limits, $31 \%-47 \%$ ), respectively, with a mean follow-up of $7.3 \pm 7$ years (Figure 6). According to univariate analysis, significant risk factors for RV dysfunction were Ebstein malformation of the TV, need for TVR, and 


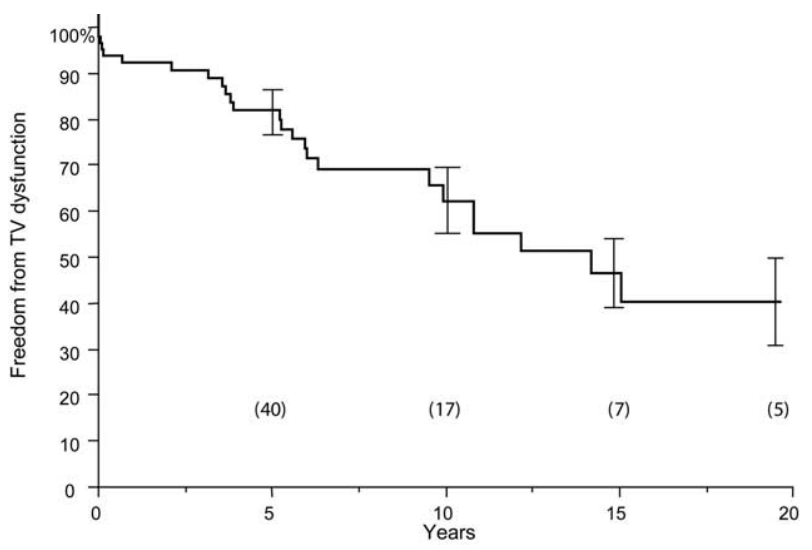

Figure 7. Freedom from tricuspid valve dysfunction after intracardiac procedure (83 patients analyzed). Numbers of patients at risk are in parentheses. Error bars indicate $70 \%$ confidence limits. $T V$, Tricuspid valve.

TABLE 4. Predictors for tricuspid valve dysfunction

\begin{tabular}{lccc}
\hline & & \multicolumn{3}{c}{$\begin{array}{c}\text { Multivariate } \\
\text { analysis }\end{array}$} \\
\cline { 3 - 5 } Variable & $\begin{array}{c}\text { Univariate } \\
\boldsymbol{P} \text { value }\end{array}$ & $\begin{array}{c}\text { Hazard } \\
\text { ratio }\end{array}$ & $\boldsymbol{P}$ value \\
\hline Ebstein malformation of TV & $<.0001$ & 3 & $<.0001$ \\
$\begin{array}{l}\text { Preoperative RV dysfunction } \\
\text { RVEDp }>17 \mathrm{~mm} \text { Hg (before } \\
\text { the operation) }\end{array}$ & .0002 & & \\
$\begin{array}{l}\text { Nonoperative group Fontan } \\
\text { pathway }\end{array}$ & .0135 & & \\
& & .0150 & \\
\end{tabular}

$\overline{T V}$, Tricuspid valve; $R V$, right ventricular; $R V E D p$, right ventricular enddiastolic pressure.

CHB. Multivariate analysis identified Ebstein malformation of the TV as a risk factor for RV dysfunction (Table 3).

\section{TV Dysfunction in Patients Undergoing Intracardiac} Procedures

TV dysfunction occurred in 36 (42\%) of 86 patients with available data (data were unavailable in 27 patients). The 1-, 5-, 10-, 15-, and 20-year freedom from TV dysfunction after an intracardiac procedure was $91 \%$ (70\% confidence limits, $87 \%-94 \%$ ), 69\% (70\% confidence limits, 63\%-74\%), 52\% (70\% confidence limits, $45 \%-59 \%$ ), $42 \%$ (70\% confidence limits, 35\%-50\%), and 37\% (70\% confidence limits, 29\%$45 \%$ ), respectively, with a median follow-up 6.7 years (Figure 7). Late development of TV dysfunction was associated with Ebstein malformation of TV. TV dysfunction was significantly more prevalent in patients not undergoing a Fontan procedure $(P=.015$, Table 4$)$. Patients requiring TVR (27 patients) either at their initial operation or later during follow-up at any time had the worse outcomes $(P<$ .001 ; hazard ratio, 4.4).
TABLE 5. Predictors for death: Operative group VSD surgery

\begin{tabular}{lc}
\hline Variable & Univariate $\boldsymbol{P}$ value \\
\hline RVEDp $>17 \mathrm{~mm} \mathrm{Hg}$ before the operation & .0002 \\
CHB & .0078
\end{tabular}

RVEDp, Right ventricular end-diastolic pressure; $C H B$, complete heart block.

TABLE 6. Predictors for death: Operative group tricuspid valve replacement

\begin{tabular}{lccc}
\hline & Univariate & \multicolumn{2}{c}{ Multivariate analysis } \\
\cline { 3 - 4 } Variable & $\boldsymbol{P}$ value & Hazard ratio & $\boldsymbol{P}$ value \\
\hline Preoperative RV dysfunction & .032 & 2,9 & .035 \\
\hline
\end{tabular}

$R V$, Right ventricular.

\section{VSD Surgery Operative Group}

Seventy-six patients underwent either VSD closure or VSD closure with relief of left ventricular outflow tract obstruction. The median age at the time of the operation was 6.3 years, with a median follow-up of 3.7 years. The 1-, 5-, 10-, and 15 -year survivals were $79 \%$ (70\% confidence limits, 74\%-85\%), 73\% (70\% confidence limits, 67\%-79\%), 67\% (70\% confidence limits, 60\%-74\%), and 67\% (70\% confidence limits, $60 \%-74 \%$ ), respectively. There was no significant difference in survival among 3 subgroups (VSD operation alone, VSD operation with relief of valvular or subvalvular pulmonic stenosis, and VSD operation with a conduit between the left ventricle [LV] and PA). Univariate analysis identified RV end-diastolic pressure of greater than $17 \mathrm{~mm} \mathrm{Hg}$ before the operation and CHB as risk factors for death (Table 5). RV dysfunction occurred in 20 (33\%) of 60 patients with available data. CHB occurred in $30(40 \%)$ patients, with 28 (37\%) cases of postoperative CHB.

\section{TVR Operative Group}

Fourteen patients underwent tricuspid valve replacement (TVR) at their first operation. The median age at the time of the operation was 4.4 years, with a median follow-up of 3.3 years. The 1- and 5-year survivals were $71 \%$ (70\% confidence limits, 59\%-83\%) and 53\% (70\% confidence limits, $39 \%-67 \%$ ), respectively. Univariate and multivariate analysis identified RV dysfunction before the operation as a risk factor for death (Table 6). The 1- and 5-year freedom from repeated TVR was $100 \%$ and $40 \%$ (70\% confidence limits, $23 \%-57 \%$ ), respectively. CHB occurred in 3 patients (2 patients with preoperative $\mathrm{CHB}$ and 1 patient with postoperative CHB). RV dysfunction was noted in 11 (79\%) patients after TVR. 


\section{Fontan Pathway}

Seventeen patients underwent a Fontan-type repair without mortality or heart block. The median age at the time of the operation was 2.2 years, with a median follow-up of 3.9 years. A Fontan procedure was performed for the following indications: straddling-overriding of the mitral valve (5 patients); straddling-overriding of the TV (6 patients); unbalanced complete atrioventricular canal with complex anatomy (3 patients); multiple VSDs (2 patients); inaccessible position of VSD (4 patients); or personal preference of the surgeon (4 patients).

\section{Discussion}

Optimal surgical management of patients with ccTGA and associated lesions remains controversial. ${ }^{3-8}$ The ability of the right ventricle to support the systemic circulation over a normal lifespan remains a serious concern. ${ }^{6,9,10}$ This report analyzes the long-term survival of a large group of patients with ccTGA who underwent repair of associated lesions at a single institution. The overall 1-, 5-, 10-, and 15-year survivals after intracardiac procedures were $84 \%, 75 \%$, $68 \%$, and $61 \%$, respectively. Significant differences were apparent among the surgical groups. Patients requiring TVR at the initial operation had the poorest outlook, whereas the best outcome was seen in patients undergoing the Fontan procedure.

\section{Risk Factors for TR and Influence on Outcome}

Significant TV regurgitation after surgical intervention occurred in $42 \%$ of patients. Late development of TV dysfunction was associated with Ebstein malformation of TV and RV dysfunction before the operation. It has been reported that significant TR develops postoperatively in many patients with corrected transposition, especially in patients with coexisting TV abnormalities., ${ }^{3,711}$ TV regurgitation results from a combination of annular dilatation and the high incidence of morphologically TV abnormalities present in these patients. RV dysfunction after surgical intervention associated with changes in RV geometry is likely to further contribute to deterioration of TV function. Increasing valvular regurgitation leading to progressive volume overload of the RV, followed by annular dilatation and further regurgitation, constitutes a reinforcing cycle of TV dysfunction. Splinting of the interventricular septum by increased morphologically left ventricular pressure either naturally by means of PS or by banding could help to maintain proper geometry of the right ventricle and could prevent progression of TV regurgitation. The favorable natural history of corrected transposition with PS in comparison with the other clinical subsets supports this argument. Other evidence is banding of the PA as an interim step in preparation of the LV for systemic function, which usually immediately improves systemic TV function because of geometric changes of the interventricular septum. Whether natural banding (PS) or banding itself in selected group of patients with ccTGA could be considered as a definitive palliation remains to be seen. In the present study, Ebstein malformation of the TV was not only a risk factor for late development of TR but also was an independent preoperative predictor of mortality. RV intolerance of the increased afterload resulting from isolated VSD closure also might contribute to the deterioration of TV function. In addition, the method for VSD closure, placing sutures on the morphologically RV side of the septum, requires suture placement either extremely close to the TV or even incorporating TV tissue. Thus, the subsequent deterioration in TV function after the surgical intervention might be not just a consequence of RV shape and size or Ebstein-like malformation but also a consequence of surgical distortion and scarring. ${ }^{12}$ On the basis of our data, deterioration of systemic RV function was not delayed by TVR. In fact, patients who required TVR at the initial operation or during the follow-up had significantly poorer outcomes. Furthermore, the need for TVR was a significant predictor of RV dysfunction. Other reports advocate replacement of the TV in patients with ccTGA at the earliest sign of increasing symptoms or progressive systemic ventricular deterioration to preserve RV function. ${ }^{7}$ Therefore, the surgical management should include consideration of earlier timing of TVR or a cardiac repair, which relieves the RV and TV, of a systemic workload. ${ }^{13}$

\section{Risk Factors for RV Dysfunction and Influence on Outcome}

The ability of the right ventricle to function as a systemic ventricle throughout a normal lifetime remains unproved. Although previous reports have demonstrated that in most cases function remains satisfactory during an intermediate period of follow-up,,$^{9,10,11,13}$ nevertheless, the 1-, 5-, 10-, $15-$, and 20 -year freedom from RV dysfunction after intracardiac procedure was $85 \%, 73 \%, 57 \%, 43 \%$, and $39 \%$, respectively. Our results demonstrate that postoperative RV dysfunction occurred in $44 \%$ of patients. Significant risk factors for RV dysfunction were Ebstein malformation of the TV, the need for TVR, and CHB. This finding is consistent with the report of Sano and colleagues, ${ }^{11}$ in which $55 \%$ of patients had RV dysfunction after an intracardiac repair. In that study, 2 factors were responsible for late development of RV dysfunction; the first, postoperative TR, is consistent with our data (need for TVR). They further demonstrated that the pulmonary to systemic flow ratio was significantly higher in patients who had RV dysfunction than in those who did not. We did not find a correlation between higher Qp/Qs and postoperative RV dysfunction, although the diagnostic group VSD+PS with limited pulmonary blood flow had the best outcome. ${ }^{11,14,15}$ 


\section{Risk Factors for CHB and Influence on Outcome}

The incidence of perioperative CHB in the present study (28\%) is comparable with that seen in other series. ${ }^{3,4,8,11}$ Patients without CHB demonstrated a significantly better outcome (84\% survival at 15 years of follow-up) compared with patients with CHB (56\% survival at 15 years of followup). The incidence of CHB significantly decreased after 1981 because of implementation of a new approach for VSD closure. ${ }^{16}$

\section{Current Strategies for Operative Approach}

Alternative surgical approaches are a single-ventricle type of repair (Fontan procedure) or an anatomic correction that maintains the left ventricle as the systemic ventricle. The present results for patients with ccTGA undergoing the Fontan procedure confirm the promising long-term outlook suggested by previous reports for this anatomic subgroup of patients. ${ }^{17}$ This approach eliminates the surgical risks of CHB and acceleration of progressive TR after VSD closure. Another potential advantage results from retaining both ventricles in the systemic circulation. In the case of complex VSD and TV anatomy or abnormal systemic or pulmonary venous return, this approach is fully justifiable, with excellent intermediate-term results. In the present study, 17 patients who underwent a Fontan procedure had the best outcome, with no deaths and no postoperative heart block with preservation of good TV function.

The main theoretical advantage of anatomic correction (double switch or Senning-Rastelli) arises from its use of the LV as the systemic pumping chamber and the mitral valve as the systemic atrioventricular valve. Performing an anatomic correction should be strongly considered for patients with TR before surgical intervention, Ebstein malformation of the TV, and RV dysfunction. ${ }^{13,18-25}$ Heart transplantation remains another option for this difficult patient population but requires immune suppression and provides an uncertain long-term outlook.

\section{Conclusions}

The long-term outcome of patients with ccTGA who have undergone a classic surgical approach is unsatisfactory. Systemic RV dysfunction and TV dysfunction predict poor outcomes for many of these patients. The poorest outcome was seen in patients who required TVR either at their initial operation or later during follow-up. Alternative surgical approaches, such as anatomic correction or the Fontan procedure, might lead to improved results, especially in the highest-risk groups. The Fontan procedure, leaving the VSD untouched, might be the preferable option if there is an unfavorable anatomic location of the VSD or straddling of the atrioventricular valves. Otherwise, the performance of an anatomic correction with the LV as the systemic ventricle should be considered. The advantages of an anatomic correction should be balanced against the potential long- term problems resulting from the atrial switch portion of the procedure.

We thank Kimberlee Geavreau, ScD, for her invaluable assistance in the statistical analysis of the data for this report.

\section{References}

1. Van Praagh R. Segmental approach to diagnosis. In: Flyer DC, editor. Nadas' pediatric cardiology. Philadelphia: Hanley \& Belfus, Inc; 1992. p. 27-35.

2. Van Praagh R, Van Praagh S. Anatomically corrected transposition of the great arteries. Br Heart J. 1967;29:112.

3. Lundstrom U, Bull C, Wyse RKH, Somerville J. The natural and "unnatural" history of congenitally corrected transposition. Am J Cardiol. 1990;65:1222-9.

4. Bove EL. Congenitally corrected transposition of the great arteries: ventricle to pulmonary artery connection strategies. Semin Thorac Cardiovasc Surg. 1995;7:139-44.

5. Di Donato RM, Wernovsky G, Jonas RA, Mayer JE Jr, Keane JF, Castaneda AR. Corrected transposition in situs inversus. Circulation. 1991;84(suppl III):III193-9.

6. Peterson RJ, Franch RH, Fajman WA, Jones RH. Comparison of cardiac function in surgically corrected and congenitally corrected transposition of the great arteries. J Thorac Cardiovasc Surg. 1988; 96:227-36.

7. Van Son JAM, Danielson GF, Huhta JC, Warnes CA, Edwards WD, Schaff HV, et al. Late results of atrioventricular valve replacement in corrected transposition. J Thorac Cardiovasc Surg. 1995;109:642-53.

8. Termignon J-L, Leca F, Vouhé PR, Vernant F, Bical OM, Lecompte $\mathrm{Y}$, et al. "Classic" repair of congenitally corrected transposition and ventricular septal defect. Ann Thorac Surg. 1996;62:199-206.

9. Connelly MS, Liu PP, Williams WG, Webb GD, Robertson P, McLaughlin PR. Congenitally corrected transposition of the great arteries in the adult: functional status and complications. J Am Coll Cardiol. 1996;27:1238-43.

10. Presbitero P, Somerville J, Rabjoli F, Stone S, Conte MR. Corrected transposition of the great arteries without associated defects in adult patients: clinical profile and follow up. Br Heart J. 1995;74:57-9.

11. Sano T, Riesenfeld T, Karl TR, Wilkinson JL. Intermediate term outcome after intracardiac repair of associated cardiac defects in patients with atrioventricular and ventriculoarterial discordance. Circulation. 1995;92(suppl II):II272-8.

12. Westerman GR, Lang P, Castaneda AR, Norwood WI. Corrected transposition and repair of associated intracardiac defects. Circulation. 1982;66(suppl I):I197-202.

13. Mee RB. Severe right ventricular failure after Mustard or Senning operation. Two-stage repair: pulmonary artery banding and switch. J Thorac Cardiovasc Surg. 1986;92:385-90.

14. Sanot T, Ogawa M, Tanihuchi K, Matsuda H, Nakajima T, Arisawa J, et al. Assessment of ventricular contractile state and function in patients with univentricular heart. Circulation. 1989;79:1247-56.

15. Graham TP Jr, Franklin RCG, Wyse RKH, Gooch V, Deanfield JE. Left ventricular wall stress and contractile function in childhood: normal value and comparison of Fontan repair versus palliation only in patients with tricuspid atresia. Circulation. 1986;74(suppl I):I61-9.

16. De Leval MR, Bastos P, Stark J, Taylor JFN, Macartney FJ, Anderson RH. Surgical technique to reduce the risk of heart block following closure of ventricular septal defect in atrioventricular discordance. J Thorac Cardiovasc Surg. 1979;78:515-26.

17. Gentles TL, Mayer JE, Gauvreau K, Newburger JW, Lock JE, Kupferschmid JP, et al. Fontan operation in five hundred consecutive patients: factors influencing early and late outcome. J Thorac Cardiovasc Surg. 1997;114:376-91.

18. Ilbawi MN, DeLeon SY, Backer CL, Duffy CE, Muster AJ, Zales VR, et al. An alternative approach to the surgical management of physiologically corrected transposition witch ventricular septal defect and pulmonary stenosis or atresia. J Thorac Cardiovasc Surg. 1990;100: 410-5.

19. Yamagishi M, Imai Y, Hoshino S, Ishihara K, Koh Y, Nagatsu M, et 
al. Surgical correction of atrioventricular discordance-results and follow-up. Nippon Kyobu Geka Gakkai Zasshi. 1992;40:1167-76.

20. Yagihara T, Kishimoto H, Isobe F, Yamamoto F, Nishigaki K, Matsuki $\mathrm{O}$, et al. Double switch operation in cardiac anomalies with atrioventricular and ventriculoarterial discordance. J Thorac Cardiovasc Surg. 1994;107:351-8.

21. Imai Y, Sawatari K, Hoshino S, Ishihara K, Nakazawa M. Ventricular function after anatomic repair in patients with atrioventricular discordance. J Thorac Cardiovasc Surg. 1994;107:1272-83.

22. Di Donato RM, Troconis CJ, Marino B, Carotti A, Iorio FS, Rossi E, et al. Combined Mustard and Rastelli operations. J Thorac Cardiovasc Surg. 1992;104:1246-8.
23. Brawn WJ, Wright JG, Sethia B, de Giovanni J, Silove ED. Atrial and arterial switch repair for corrected transposition and ventricular septal defect witch severe tricuspid valve regurgitation [abstract]. Cardiol Young. 1993;3(suppl):I58.

24. O Stumper O, Wright JGC, De Giovanni JV, Silove ED, Sethia B, Brawn WJ. Combined atrial and arterial switch procedure for congenital corrected transposition with ventricular septal defect. Br Heart J. 1995; 73:479-82.

25. Jonas RA, Giglia TM, Sanders SP, Wernovsky G, Nadal-Ginard B, Mayer JE, et al. Rapid two-stage arterial switch for transposition of the great arteries and intact ventricular septum beyond the neonatal period. Circulation. 1989;80(suppl I):I203-8.

\section{Appendix 1. Associated cardiovascular anomalies in patients undergoing repair of L-TGA}

\begin{tabular}{|c|c|c|}
\hline Anomaly & $\begin{array}{c}\text { No. of } \\
\text { patients }\end{array}$ & $\%$ \\
\hline Ventricular septal defect & 108 & 88 \\
\hline Membranous & 45 & 37 \\
\hline Conoventricular & 47 & 38 \\
\hline Inlet type & 16 & 13 \\
\hline Inlet + conoventricular & 4 & 3 \\
\hline Muscular & 5 & 4 \\
\hline Multiple & 5 & 4 \\
\hline Pulmonic stenosis & 58 & 47 \\
\hline Valvular & 49 & 40 \\
\hline Subvalvular & 51 & 39 \\
\hline Pulmonary atresia & 38 & 31 \\
\hline Tricuspid valve abnormality & 36 & 29 \\
\hline Ebstein malformation & 23 & 19 \\
\hline Straddling & 4 & 3 \\
\hline Overriding & 4 & 3 \\
\hline Atrioventricular canal & 7 & 5 \\
\hline Mitral valve abnormality & 7 & 5 \\
\hline Straddling & 3 & 3 \\
\hline Cleft & 4 & 3 \\
\hline Atrioventricular canal & 7 & 5 \\
\hline Complete atrioventricular canal & 7 & 6 \\
\hline Atrial septal defect-secundum & 68 & 55 \\
\hline Coarctation of aorta & 6 & 5 \\
\hline Total anomalous pulmonary venous drainage & 4 & 3 \\
\hline Left (right) superior vena cava to coronary sinus & 21 & 17 \\
\hline Interrupted inferior vena cava & 9 & 7 \\
\hline Patent ductus arteriosus & 41 & 33 \\
\hline Abnormal coronary pattern & 1 & 0.8 \\
\hline Double-outlet right ventricle & 22 & 18 \\
\hline Criss-cross heart & 1 & 0.8 \\
\hline Aortopulmonary collaterals & 3 & 3 \\
\hline Abdominal heterotaxy & 10 & 8 \\
\hline Others & 12 & 10 \\
\hline
\end{tabular}

Patients were counted in multiple subcategories. L-TGA, Corrected transposition of the great arteries. 


\section{Appendix 2. Patient- and procedure-related variables}

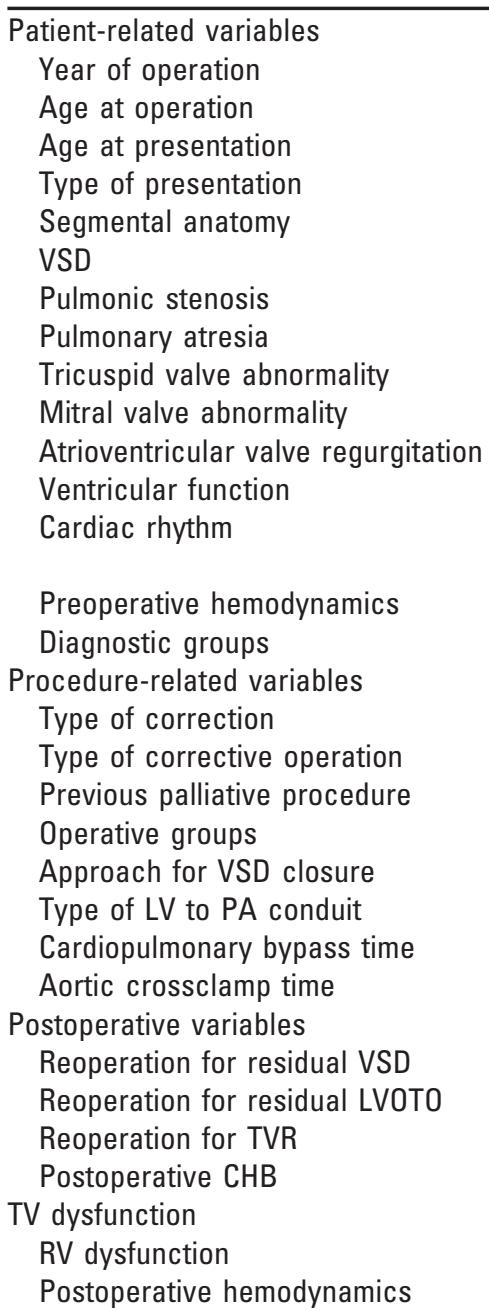

Cyanosis, CHF, asymptomatic

$\{S, L, L\} ;\{I, D, D\}$

Membranous, conoventricular, inlet type, muscular, multiple

Valvular, subvalvular

Yes/no

Ebstein malformaton, straddling, cleft, overriding

Straddling, overriding, cleft

None, trivial, mild, moderate, severe

Normal, mildly, moderately, severe decreased

SR; first-, second- and third-degree block; atrial flutter; atrial fibrillation; Wolfe-Parkinson-

White syndrome

LAp, RAp, RVEDp, LVEDp, Qp, Os, Qp/0s

VSD + PS, VSD + PA, VSD, VSD + TR, TR, others

Palliative, corrective

Fontan pathway, 2-ventricle repair

Shunt, band, PA plasty

VSD surgery, TVR or TV plasty, other

Trans RA, LV, RV, Ao, PA, LA

Allograft, porcine valved xenograft, Dacron tube

Yes/no

Yes/no

Yes/no

Yes/no

TVR or TV insufficiency mild or greater

Worse after surgical intervention with mildly or more decreased function LAp, RAp, RVEDp, LVEDp,

$C H F$, Congestive heart failure; $V S D$, ventricular septal defect; $S R$, sinus rhythm; $L A p$, left atrial pressure; $R A p$, right atrial pressure; $R V E D p$, right ventricular end-diastolic pressure; $L V E D p$, left ventricular end-diastolic pressure; $Q p$, pulmonary flow; $Q s$, systemic flow; $Q p / Q$ s, pulmonary to systemic flow ratio $V S D+P S$, ventricular septal defect plus pulmonary stenosis; $V S D+P A$, ventricular septal defect plus pulmonary atresia; $V S D+T R$, ventricular septal defect plus tricuspid regurgitation; $T R$, tricuspid regurgitation; $L V$, left ventricle; $P A$, pulmonary atresia; $R A$, right atrium; $R V$, right ventricle; $A$ o, aorta; $L A$, left atrium; LVOTO, left ventricular outflow tract obstruction; TVR, tricuspid valve replacement; $C H B$, complete heart block; $T V$, tricuspid valve. 
Appendix 3. Causes of early and late death $(n=30)$

No. of

patients

Early failure $(\mathrm{n}=15$ )

Could not be weaned from CPB

Sepsis

Cardiac failure

Cerebral damage

Arrhythmia

Prosthetic TV stuck in the open position

Inadequate shunt

Late failure $(n=15)$

Arrhythmia

Biventricular failure

After heart transplantation

Inadequate shunt

Hemoptysis
$\%$ of deaths

20

127

$5 \quad 33$

2 13

2 13

1 7

$1+7$

213

$10 \quad 66$

$1+7$

127

$1+7$

$\overline{C P B}$, Cardiopulmonary bypass; $T V$, tricuspid valve. 